\title{
Evaluation of Durability Conferred by an Oleothermic Treatment on Chestnut and Douglas fir through Laboratory and in Field Tests
}

\author{
Sabrina Palanti \\ CNR IVALSA, Consiglio Nazionale delle Ricerche Istituto per la Valorizzazione del Legno e delle Specie \\ Arboree, Sesto Fiorentino, Italy \\ Email: palanti@ivalsa.cnr.it
}

Received December $11^{\text {th }}, 2012$; revised February $11^{\text {th }}, 2013$; accepted February $27^{\text {th }}, 2013$

\begin{abstract}
Copyright (C) 2013 Sabrina Palanti. This is an open access article distributed under the Creative Commons Attribution License, which permits unrestricted use, distribution, and reproduction in any medium, provided the original work is properly cited.
\end{abstract}

\begin{abstract}
The research evaluated two wood species, chestnut and Douglas fir, that are widespread in Tuscany, treated with an oleothermicprocess. Efficacy of this treatment against fungal decay was assessed through laboratory and field tests. The aim of this research was to investigate if an oleothermic process could add value to these natural resources when utilized in Use Class 4 (EN 335) for agricultural purposes such as vineyard poles. The treatment was effective on sapwood of both wood species in laboratory test, giving a protection similar to the untreated heartwood but in case of chestnut, it was easily washed away. In field test the leaching during the outdoor exposure reduced the resistance to fungal decay in both species.
\end{abstract}

Keywords: Conferred Durability; Chestnut; Douglas fir; Oleothermic Treatment

\section{Introduction}

The conventional wood protection for Use Classes 3 and 4 according to EN 335 (2006) is actually based on broad spectrum biocide formulations such as copper/organic biocides, copperorganometallics, metal free preservatives (Hughes 2004), and alkyl ammonium compounds (Pernak et al. 2004).

In the last decade, there has been a great interest within Europe in oils and water repellents for wood preservation princepally focusing on screening of natural and synthetic oils (Sailer and Rapp 2001; Van Eckeveld et al. 2001; Palanti et al. 2004), and on the processes for development of wood preservation technology (Thevenon 2001; Treu et al. 2001). Chestnut and Douglas fir are widely planted in Tuscany. Tuscany forest contains 862 hectares with $21 \%$ of chestnut and $4 \%$ conifers principally pine, Douglas fir and silver fir (Sanchez et al. 2005). Promoting the use of these species for agricultural purpose could add value to this natural resource.

Oleothermic treatment was explored for improving the natural durability of these species (Grenier et al. 2003). This process has been known as eco-friendly, biocide-free, cheaper, capable of being applied without drying the wood.

Oleothermic treatment also prevented the tannin leaching from chestnut which could maintain natural durability for a longer period (Grenier et al. 2003). While these results are promising, there is few data on the long-term performance of oleothermic treated chestnut and Douglas fir heartwood and sapwood. In order to evaluate these materials the following test were performed:

1) Laboratory tests of chestnut and Douglas fir sapwood, treated with oleothermic treatment, in according to EN 113 and
EN 84.

2) Natural durability test in according to EN 252 (in field) of Chestnut and Douglas fir.

3) Resistance test in according to EN 252 of treated Chestnut and Douglas fir.

\section{Materials and Methods}

\section{Wood Species}

The tested wood species were chestnut (Castanea sativa Mill.) and Douglas fir (Pseudotsugamenziesii Mirb. Franco) of Tuscan origin, from Casentino, a valley near Arezzo. The reference controls were Scots pine (Pinus sylvestris L.) and European beech (Fagus sylvatica L.), sapwood, in accordance with European norms EN 350-1:1996 and EN 113:1996 and EN 252: 1989.

\section{Treatment}

The oleothermic treatment was performed at CIRAD in Montpellier, France using a two-step process (Grenier et al. 2003).

Chestnut and Douglas fir planks were conditioned at $20^{\circ} \mathrm{C}$ and $65 \% \mathrm{RH}$, cut in samples and sent to the plant for oleothermic treatment.

The treated samples were then conditioned to constant weight at $20^{\circ} \mathrm{C}$ and $65 \% \mathrm{RH}$.

\section{Laboratory Test}

Wood blocks $(50 \pm 0.5) \times(25 \pm 0.5) \times(15 \pm 0.5) \mathrm{mm}^{3}$, were 
cut from the boards.

Natural durability and the durability conferred by oil treatment of chestnut and Douglas fir were assessed in accordance with European standards EN 113 and EN 350. A comparison of resistance against fungi before and after leaching in accordance with EN 84 was carried out.

The fungi utilized for chestnut and Douglas fir were two brown rots, Coniophora puteana (Schumacher ex Fries) Karsten, strain BAM Ebw. 15 and Gloeophyllum trabeum (Persoon ex Fries) Murril, strain BAM Ebw. 19. The white rot fungus, Coriolus versicolor (Linnaeus) Quélet, strain CTB 863 A was only utilized for chestnut. The brown rot fungus Poria placenta (Fries Cooke) sensu J. Eriksson, strain FPRL280 was utilized for Douglas fir. These fungire present the certificated ones utilized in the European normative.

The wood samples were exposed to fungal attack for 16 weeks in a conditioning room $\left(22^{\circ} \mathrm{C} \pm 2{ }^{\circ} \mathrm{C}, 70 \% \pm 5 \% \mathrm{RH}\right)$. For each set, a treated sample was placed with a reference untreated sample in a Kolle flask containing one of the test fungi growing on $20 \mathrm{ml}$ of $4 \%$ malt and $2.5 \%$ agar medium. Another set of five untreated wood specimens was used to check for strain virulence for each tested fungus.

The resistance against fungi was evaluated using mass loss of wood, which was calculated for each individual block as the difference between the dry mass before and after the fungal exposure. The minimum of mass loss on reference wood blocks were $30 \%$ for C. puteana and $20 \%$ for P. placenta, G. trabeum and $T$. versicolor.

The natural durability class was calculated according to CEN/TS 15083, expressed as durability class, against wood destroying basidiomycetes fungi based on the higher median mass loss determined for all test specimens exposed to each of the three test fungi. Using the following scale: 1- very durable (mass loss $\leq 5 \%$ ), 2- durable (mass loss $>5 \%$ to $\leq 10 \%$ ), 3 moderately durable (mass loss $>10 \%$ to $\leq 15 \%$ ) 4- slightly durable (mass loss $>15 \%$ to $\leq 30 \%$ ), 5 - not durable (mass loss $>$ $30 \%)$.

\section{Leaching in Accordance with EN 84}

Wood samples, see Table 1, were subjected to leaching according to EN 84: 1996. The cycle consisted of an initial $4 \mathrm{kPa}$ vacuum - atmospheric pressure cycle with deionized water EN ISO 3696 (1996). The wood specimens were maintained in water (ratio of water to wood 5:1) for 14 days with 9 water changes, and then conditioned to constant mass before being exposed to one of the test fungus.

\section{Table 1.}

Median mass losses \% of non-treated Chestnut heartwood or sapwood that was oleotheric treated. Samples were exposed to 3 fungi of EN 113 (H: heartwood, S: sapwood, T: Treated, L: leached, Y: yes, N:not, D class: durability class ).

\begin{tabular}{|c|c|c|c|c|c|c|}
\hline \multirow{2}{*}{$\begin{array}{l}\mathrm{H} / \\
\mathrm{S}\end{array}$} & \multirow{2}{*}{$\begin{array}{c}\mathbf{T} \\
\mathbf{Y} / \mathbf{N}\end{array}$} & \multirow{2}{*}{$\begin{array}{c}\mathbf{L} \\
\mathbf{Y} / \mathbf{N}\end{array}$} & \multicolumn{3}{|c|}{$\begin{array}{c}\text { Median mass loss \% } \\
(\mathrm{n}=5)\end{array}$} & \multirow{2}{*}{$\begin{array}{l}\text { D } \\
\text { class }\end{array}$} \\
\hline & & & $\begin{array}{c}\text { C. } \\
\text { puteana }\end{array}$ & $\begin{array}{c}C . \\
\text { versicolor } \\
\end{array}$ & $\begin{array}{c}G . \\
\text { trabeum }\end{array}$ & \\
\hline $\mathrm{S}$ & $\mathrm{Y}$ & $\mathrm{N}$ & 1.24 & 1.49 & - & 1 \\
\hline $\mathrm{S}$ & Y & $\mathrm{Y}$ & 12.91 & 12.50 & 12.92 & 3 \\
\hline $\mathrm{H}$ & $\mathrm{N}$ & $\mathrm{N}$ & 1.33 & 1.17 & 0.92 & 1 \\
\hline $\mathrm{H}$ & $\mathrm{N}$ & $\mathrm{Y}$ & 3.41 & 3.39 & 3.10 & 1 \\
\hline
\end{tabular}

\section{In Field Test}

In ground performance tests were performed in accordance with EN 252: 1989 over a 70 months period (July 2005 to April 2011). The test site was on an agricultural soil situated in Tuscany, Cesa, Val di Chiana Arezzo.

Fifteen stakes for wood species, dimensions $(500 \pm 1) \times(50$ $\pm 3) \times(25 \pm 0.3) \mathrm{mm}^{3}$, derived from heartwood chestnut, heartwood and sapwood Douglas fir were conditioned and cut before being sent to the plant for oleothermic treatment.

The treated stakes were placed vertically in the soil leaving half of length exposed.

Untreated stakes of Scots pine and beech were also buried up to half their length in the soil test site as reference controls.

Fungal decay was annually evaluated in the area around the ground contact. Inspections were carried out by giving a light blow to the upper part of each stake to determine if the stake was close to failure, followed by removal from the ground. Surface examination was probed with an awl to detect weakness due to fungal rot. Fungal decay was evaluated on the basis of the depth of fungal softening and damaged area according to a specific rating system: 0 sound, 1 slight attack, 2 moderate attack, 3 severe attack and 4 failure (stake breaks in the ground after blowing). The evaluation was performed in accordance with guideline for EN 252 of the Nordic Wood Preservation Council (Borsholt and Henriksen, 1992).

It is possible to calculate the mean life as indicated in standard EN 350-1 when all stakes fail. The mean life, where not all stakes have reached the end of their life, can be predicted using the procedure of Purslow, 1976.

The number of replicates utilized for calculating average decay grade was unequal for wood species and treatments because some stakes failed as the test site who maintained and it was not possible to determine whether decay was the sole cause of failure.

\section{Statistical Analyses}

Analysis of variance (ANOVA) one-way, ANOVA multiple factors way and a post-hoc Tukey HSD multiple comparisons of means were carried out with open source R software.

The statistical analyses were on the following tests:

Laboratory test: chestnut and Douglas fir mass loss \% of blocks exposed to $C$. puteana.

Field test: chestnut decay rating after six year; Douglas stakes rating of third (mid-term evaluation) and sixth year.

\section{Results and Discussion}

\section{Laboratory Tests}

\section{Chestnut}

Average uptake of oleothermic treatment on sapwood $(n=39)$ was $13 \%$ as $(\mathrm{m} / \mathrm{m}) \%$.

The results obtained by natural and the conferred durability are reported in Table 1. Results due G. trabeum were omitted because the beech reference wood blocks had mass losses lower than minimum required by the standard.

The oleothermic treatment provided a good protection to sapwood but it was not fixed very well. Durability rating decreased from 1 to 3 when the wood was leached in accordance with ageing procedure EN 84. Durability of non-leached treated was similar to the inherent durability of non-leached heartwood. Weight losses of non-treated heartwood samples increasedwith 
leaching procedure, but the increase did not affect the durability class.

The one-way analysis of variance (Anova) of mass loss \% of different treatment against $C$. puteana, indicated that there were significant differences between samples $\left(\mathrm{F}_{3,16}=2.2 \mathrm{e}-16^{* * *}\right)$. The post hoc Tukey multiple comparisons of means, at a $95 \%$ family-wise confidence level, showed a significant difference in leached and non-leached treated chestnut underlined that the oleothermic gave a good durability (Table 2). In leached and non-leached heartwood the significant difference depended on leaching procedure that washed away the natural extractives. It was also interesting observe that only pair with not significant difference was untreated heartwood and treated sapwood where it was found a similar grade of effectiveness when exposed to $C$. puteana. This fact confirmed that sapwood treated with oleothermic treatment reached the same grade of durability of the heartwood.

\section{Douglas fir}

The average oleothermic uptake $(n=4)$ in sapwood and heartwood were $16 \%$ and $14 \% \mathrm{~m} / \mathrm{m} \%$ respectively.

The oleothermic treatment gave a good protection to Douglas fir sapwood, improving durability to class 2 (Table 3 ) in both leached and non-leached blocks.

In the untreated Douglas fir heartwood the leaching procedure determined a decreasing in durability from class 2 to 4 . Probably this low durability was due to the fact that the leaching procedure washed away most part of the extractives.

Table 2.

Post hoc Tukey multiple comparisons of means at a $95 \%$ family-wise confidence level. T: treated, U untreated, L Leached, S sapwood, H heartwood.

\begin{tabular}{ccccc}
\hline Pair & $\begin{array}{c}\text { Mean } \\
\text { differ- } \\
\text { ence }\end{array}$ & $\begin{array}{c}\text { Lower } \\
\text { bound }\end{array}$ & $\begin{array}{c}\text { Upper } \\
\text { bound }\end{array}$ & $\begin{array}{c}\text { p value at } \\
\text { a 95\% } \\
\text { confident } \\
\text { level }\end{array}$ \\
\hline TSL-TS & 11.692 & 10.7594919 & 12.624508 & 0.0000000 \\
UH-TS & 0.116 & -0.8165081 & 1.048508 & 0.9839834 \\
UHL-TS & 2.396 & 1.463491 & 3.328508 & 0.0000089 \\
UH-TSL & -11.576 & -12.5085081 & -10.643492 & 0.0000000 \\
UHL-TL & -9.296 & -10.2285081 & -8.363492 & 0.0000000 \\
UHL-UH & 2.280 & 1.3474919 & 3.212508 & 0.0000164 \\
\hline
\end{tabular}

\section{Table 3.}

Median mass loss \% of Douglas fir (H: heartwood, S: sapwood, T: Treated, L: leached, Y: yes, N:not). In the brackets the number of samples utilized for the determination of the medians are reported.D class: Durability class.

\begin{tabular}{ccccccc}
\hline \multirow{2}{*}{$\mathbf{H} /$} & $\mathbf{T}$ & $\mathbf{L}$ & \multicolumn{3}{c}{ Median Mass loss \% } & D \\
\cline { 5 - 6 } S & $\mathbf{Y} / \mathbf{N}$ & $\mathbf{Y} / \mathbf{N}$ & $\begin{array}{c}\text { C. } \\
\text { puteana }\end{array}$ & $\begin{array}{c}\boldsymbol{G} . \\
\text { trabeum }\end{array}$ & $\begin{array}{c}\boldsymbol{P} . \\
\text { placenta }\end{array}$ & \\
\hline $\mathrm{S}$ & $\mathrm{Y}$ & $\mathrm{N}$ & $1.37(2)$ & - & $7.67(2)$ & 2 \\
$\mathrm{~S}$ & $\mathrm{Y}$ & $\mathrm{Y}$ & $7.42(5)$ & $3.62(3)$ & $5.91(4)$ & 2 \\
$\mathrm{H}$ & $\mathrm{N}$ & $\mathrm{N}$ & $3.88(3)$ & $3.79(2)$ & $9.03(4)$ & 2 \\
$\mathrm{H}$ & $\mathrm{N}$ & $\mathrm{Y}$ & $12.37(3)$ & $1.45(4)$ & $19.67(2)$ & 4 \\
$\mathrm{~S}$ & $\mathrm{~N}$ & $\mathrm{~N}$ & $11.26(4)$ & $5.02(2)$ & $13.89(4)$ & 3 \\
\hline
\end{tabular}

The set of untreated sapwood gave reaching the durability class 3 (Table 2).

The one-way analysis of variance (Anova) of mass loss showed that there were significant difference among treatments with fungus $C$. puteana, gave significant differences between means $\left(\left(\mathrm{F}_{6,16}=0.784800 * *\right)\right.$. The post hoc Tukey multiple comparisons of means, $95 \%$ family-wise confidence level, evidenced significance in the mass loss in all combination with the exclusion of the pairs untreated heartwood-treated and leached sapwood, untreated heartwood-treated sapwood. The efficacy of treatment when applied into sapwood, and its fixation is evidenced by not significance between untreated heartwoodtreated and leached sapwood.

\section{In Field Test}

\section{Chestnut}

The year-by-year results obtained by in field test of chestnut are reported in Table 4.

Only a slight difference was observed between treated and non-treated chestnut stakes. Four of eight treated stakes failed (decay grade 4) at the end of the test, and the mean life of these stakes was six years. Five of twelve untreated chestnut failed at sixth year with a mean life of 6 years, the number of ruptures was 6 on 12 and the mean life was, as well as treated ones, six years. The beech control stakes all failed after two years.

The analysis of variance of the decay grade of 68 months evidenced significant difference between treated and nontreated samples $\left(\mathrm{F}_{2,27}=0.03873^{*}\right)$. The post hoc Tukey multiple comparisons of means at $95 \%$ family-wise confidence level, indicated that there are significant differences in decay grade were weather untreated chestnut and beech.

\section{Douglas fir}

In the Table 5 are reported the overall results obtained from Douglas fir stakes.

In the treated heartwood, at the end of the test, six stakes on eight reached the rupture with a mean life 5.33 years. In the treated Douglas fir sapwood set at the end of the test 9 on 10 stakes reached the decay grade 4 with a mean life 5.11 years. The Douglas fir untreated set sapwood reached a mean life 4.60 years. In the untreated heartwood set only two stakes on 10 reached the rupture.

The decay grade of 68 months evidenced significance between samples $\left(\mathrm{F}_{4,38}=0.00064^{* * *}\right)$ and the post hoc Tukey multiple comparisons of means, $95 \%$ family-wise confidencelevel, gave as significant the pairs untreated Douglas fir

Table 4.

Decay rating of average annual evaluations of Chestnut in field testing.

\begin{tabular}{cccc}
\hline \multirow{2}{*}{$\begin{array}{c}\text { Exposition } \\
\text { time (month) }\end{array}$} & $\begin{array}{c}\text { Treated } \\
\text { Chestnut, } \\
\text { heartwood }\end{array}$ & $\begin{array}{c}\text { Untreated } \\
\text { Chestnut, } \\
\text { heartwood }\end{array}$ & Beech \\
\cline { 2 - 4 } 13 & 0.23 & 0.21 & 2.1 \\
23 & 0.25 & 1.00 & 3.6 \\
36 & 1.13 & 1.57 & 3.9 \\
47 & 1.75 & 2.21 & 4.0 \\
62 & 2.25 & 2.50 & Failed \\
68 & 3.38 & 3.29 & Failed \\
\hline
\end{tabular}


Table 5.

Decay rating of field average annual evaluations of Douglas fir.

\begin{tabular}{cccccc}
\hline \multirow{2}{*}{$\begin{array}{c}\text { Exposition } \\
\text { time (month) }\end{array}$} & $\begin{array}{c}\text { Treated Douglas fir } \\
\text { sapwood }\end{array}$ & $\begin{array}{c}\text { Treated Douglas fir } \\
\text { heartwood }\end{array}$ & $\begin{array}{c}\text { Average decay rating } \\
\text { Untreated Douglas fir } \\
\text { sapwood }\end{array}$ & $\begin{array}{c}\text { Untreated Douglas fir } \\
\text { heartwood }\end{array}$ & Scot pine sapwood \\
\hline 13 & 1.09 & 0.11 & 1.00 & 0.30 & 0.3 \\
23 & 1.36 & 0.78 & 1.29 & 1.00 & 1.1 \\
36 & 1.55 & 1.44 & 2.29 & 1.70 & 4 \\
47 & 2.80 & 2.63 & 3.14 & 2.20 & 4 \\
62 & 2.90 & 2.63 & 3.14 & 2.40 & Failed \\
68 & 3.89 & 3.75 & 3.71 & 3.11 & Failed \\
\hline
\end{tabular}

heart wood-treated Douglas fir sapwood, untreated Douglas fir heartwood-treated Douglas fir heartwood and Scot pine-untreated Douglas fir heartwood.

\section{Conclusion}

The results showed that oleothermic treatment improved the durability of chestnut and Douglas fir, both laboratory and fields exposition. Oleothermic treatment provided a good protection to chestnut sapwood as evidenced by laboratory experiments, but the treatment it was susceptible to the leaching during the field test.

With regarding Douglas fir field test is remarkable that the significant difference observed in the pair heartwood treated and not treated was due also to the presence of natural extractives inside the wood, responsible for the conferred durability. The protection given by oil was susceptible to leach and further studies are recommended to develop methods for fixing the treatment.

\section{Acknowledgements}

The author thanks the Regional Agency for Agriculture Developing and Innovation (ARSIA) that supported this research, CIRAD for theoleothermic treatment, and Mrs. Anna Maria Torniai from CNR Trees and Timber Institute who helped with fungi cultures.

\section{REFERENCES}

Borksholt, E., \& Henriksen, H. K. (1992). Guideline for EN 252: Field test method for determining the relative protective effectiveness of wood preservatives in ground contact NWPC Information No. 23/90 ISSN 0358-707X.

CEN EN 113 (1996). Wood preservatives. Test method for determining the protective effectiveness against wood destroying basidiomycetes. Determination of the toxic values. Brussels: European Committee for Standardisation.

CEN EN 252 (1989). Field test method for determining the relative protective effectiveness of a wood preservative in ground contact. Brussels: European Committee for Standardisation.

CEN EN 84 (1996). Wood preservatives. Accelerated ageing of treated wood prior to biological testing-Leaching procedure. Brussels: European Committee for Standardisation.

CEN EN 335 (2006). Durability of wood and wood-based productsDefinition of use classes-Part 1: General. Brussels: European Committee for Standardisation.

CEN EN ISO 3696 (1996). Water for analytical laboratory use. Specification and test methods. Brussels: European Committee for Standardisation.

CEN EN 350-1 (1996). Durability of wood and wood-based products.
Natural durability of solid wood. Guide to the principles of testing and classification of natural durability of wood. Brussels: European Committee for Standardisation.

CEN/TS 15083-1 (2005). Durability of wood and wood-based products Determination of the natural durability of solid wood against wooddestroying fungi, test methods. Part 1: Basidiomycetes. Brussels: European Committee for Standardisation.

Grenier, D., Bailleres, H., Meot J., Langbour, P., \& Lanvin, J.-D. (2003). A study of water loss and oil adsorption during oleothermic treatment of wood. Proceeding of the 1st European Conference on Wood Modification, Belgium, 23-32.

Hughes, A. (2004). The tools at our disposal. Lisbon: Final Workshop Cost Action E22.

Militz, H., Krause, A., \& Hof, C. (2004). Modified wood for window and cladding products. In A. Ceccotti (Ed.), Proceeding of International Symposium on Advanced Timber and Timber Composite Elements for Building, Florence: CNR-Ivalsa.

Palanti, S., \& Susco, D. (2004). A new wood preservative based on heated oil treatment combined with triazole fungicides developed for above-ground conditions. International Biodeterioration \& Biodegradation, 54, 337-342. doi:10.1016/j.ibiod.2004.04.003

Pernak, J., Zabielska-Mateljuc, J., Kropacs, A., \& Foksowicz-Flaczyk, J. (2004). Ionic liquid in wood preservation. Holzforschung, 52, 286291.

Purlow, D.F. (1976). Result of field test on the natural durability of timber (1932-1975). Building Research Establishment Current Paper CP 6/76, Garston.

Sailer, M., \& Rapp, A.O. (2001). Water repellency of some natural oil. Workshop and Meetings of European COST (Cooperation in the field of the Scientific and Technical Research). Action E22-Environmental Optimisation of Wood Protection. Reinbek.

Sanchez, D., Leinonen, A., Vesterinen P., Capaccioli, S., Gil, J., \& Echeverria, I. (2005). Bio-south: Techno-economical assessment of production and use of biofuels for heating and cooling applications in south Europe. 14th European Biomass Conference, 17-21 October 2005, Paris.

Thevenon, M. F. (2001). Oils and water repellents in wood protection research and development in France. Reinbek: Workshop on Optimising treatment levels and managing environmental risks, Cost E22.

Treu, A., Militz, H., \& Breyne, S. (2001). Royal treatment-scientific background and practical application. Reinbek: Workshop on Optimising Treatment Levels and Managing Environmental Risks, Cost E22.

Van Eckeveld, A., Homan, W., \& Militz, H. (2001). Water repellency of some natural oil. Workshop and Meetings of European COST (Cooperation in the field of the Scientific and Technical research). Reinbek: Action E22-Environmental Optimisation of Wood Protection.

Vernois, M. (2001). Heat treatment of wood in France-State of art in rewiew on heat treatments of wood. In A. O. Rapp (Ed.), Proceeding of the Special Seminar COST E22, Antibes. 